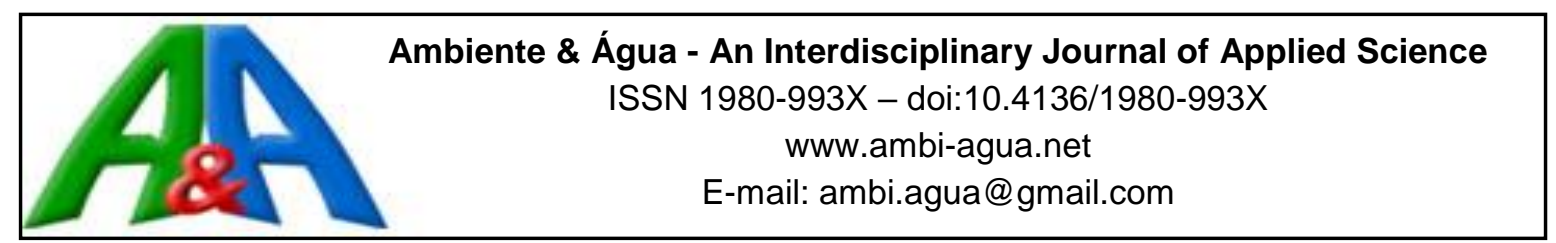

\title{
Erosividade da chuva em Rondon do Pará, PA, Brasil de 1999 a 2015 e projetada para 2035
}

\author{
doi:10.4136/ambi-agua.1956
}

Received: 14 Jun. 2016; Accepted: 22 Sep. 2016

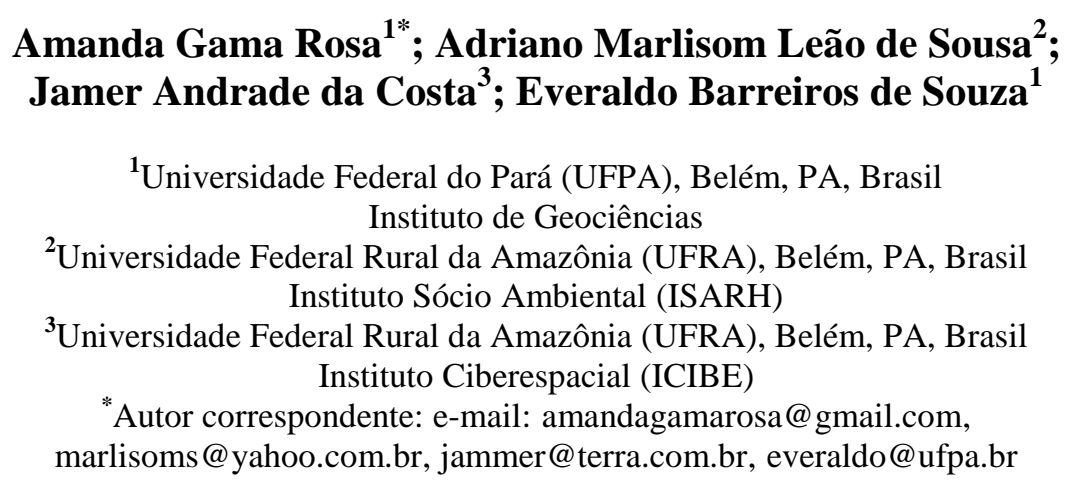

\section{RESUMO}

Visando contribuir com informações acerca das perdas de solo em Rondon do Pará, este trabalho determinou o valor de erosividade da chuva para a área urbana deste município, sua probabilidade de ocorrência e de seu período de retorno projetados para os próximos 20 anos. Foram realizadas análises da distribuição anual do índice de erosividade e verificadas as correlações entre o índice de erosividade médio mensal com o coeficiente de chuva. Para isto, obtiveram-se dois tipos de dados de precipitação: 1) observados, dos satélites CMORPH, de 1999 a 2015; e 2) por modelagem, RegCM4, de 2016 a 2035. Com base nestes dados, a erosividade foi calculada com os dados mensais e anuais de precipitação. Distribuições de frequência dos valores de erosividade e seus períodos de retorno foram calculados e plotados em curvas de probabilidades de ocorrência. Foram feitas análises de regressão entre a precipitação e a erosividade. No período de 1999 a 2015, o valor do fator R para Rondon do Pará foi $16.390 \mathrm{MJ} \mathrm{mm} \mathrm{ha} \mathrm{h}^{-1} \mathrm{ano}^{-1}$, com probabilidade de $47 \%$ de ser igualado ou superado pelo menos uma vez a cada 2,1 anos. No período de 2016 a 2015, o valor de R foi $13.038 \mathrm{MJ}$ $\mathrm{mm} \mathrm{ha} \mathrm{h}^{-1} \mathrm{ano}^{-1}$. Entre fevereiro a abril e janeiro a abril, são prováveis as maiores perdas de solo para 1999-2015 e 2016-2035, respectivamente. O modelo matemático de regressão que apresentou melhor resultado foi o de potência para os anos de 1999 a 2015 e o de polinômio para os anos de 2016 a 2035.

Palavras-chave: erosão, planejamento conservacionista, regime de precipitação.

\section{Rainfall erosivity in Rondon do Pará, PA, Brazil from 1999 to 2015 and projected to 2035}

\begin{abstract}
This study determined the rainfall erosivity value for the urban area of Rondon do Pará in order to provide information about the city's soil loss. The study also determined the probability of erosion occurrence and the return period projected for the next 20 years. The
\end{abstract}


annual distribution of the erosivity index was analyzed and an estimate was made of the correlation between the average monthly erosivity index and the rainfall coefficient. To accomplish this, two types of rainfall data were obtained: 1) data observed by the CMORPH satellites from 1999 to 2015; and 2) data modelled by the RegCM4 model from 2016 to 2035. Erosivity was calculated based upon these monthly and annual rainfall data. Frequency distributions of erosivity values and their return periods were calculated and probability curves were plotted. Regression analyses between precipitation and erosivity were completed. In the period from 1999 to 2015, the value of the R factor of Rondon do Pará was 16,390 MJ $\mathrm{mm} \mathrm{ha} \mathrm{h}^{-1} \mathrm{~h}^{-1} \mathrm{an}^{-1}$, with a probability of $47 \%$ of being equaled or exceeded at least once each 2.1 years. In the period from 2016 to 2015 , the $\mathrm{R}$ value was $13,038 \mathrm{MJ} \mathrm{mm} \mathrm{ha}^{-1} \mathrm{~h}^{-1} \mathrm{year}^{-1}$. Highest soil losses are probable between February and January from 1999 to 2015 and between January and April from 2016 to 2035. The regression mathematical models that had the best results were the potency and the polynomial models for the years from 1999 to 2015 and 2016 to 2035 , respectively.

Keywords: conservation planning, erosion, precipitation regime.

\section{INTRODUÇÃO}

Os desastres naturais compõem um tema cada vez mais presente no cotidiano da sociedade. Existe um aumento significativo não apenas na frequência e intensidade destes desastres, mas também nos impactos gerados (CEPED, 2013). Muitos destes desastres são intensificados pelo crescimento acelerado e desordenado das cidades associado com a falta de planejamento urbano, o que tem potencializado as situações de risco em eventos naturais, causando desastres (Mello et al., 2006). Um exemplo destes é o evento de erosão, caracterizado por um processo mecânico de desagregação, transporte e deposição de materiais pela ação da água, ventos ou gelo, que pode ocorrer em superfície e profundidade, sob condições físicas naturalmente relevantes, porém que pode se tornar crítico em função da ação antrópica (Silva e Machado, 2014). A erosão hídrica, tipo de erosão mais comum no Brasil, e a consequente produção de sedimento têm sido preocupação constante no que se diz respeito à gestão do solo e da água, com grande potencial de ocasionar problemas de ordem ambiental, econômico e social relevantes ao equilíbrio de ecossistemas em uso (Santos et al., 2010).

Desde muito tempo, trabalhos como o de Brown (1984) alertavam sobre as consequências da intensificação do uso do solo, seja pela agricultura ou urbanização, exercendo forte pressão sobre este, o que coloca em risco o atendimento das necessidades humanas e ambientais em virtude da aceleração das taxas de erosão. Assim, é inadiável equacionar e propor soluções para este problema. Nesse sentido, a modelagem do processo de erosão é essencial como uma estratégia usada no planejamento do uso, manejo e conservação do solo.

A Equação Universal da Perda de Solo (EUPS) é um modelo empírico de estimativa de perdas médias anuais de solo em um local, possibilitando um planejamento conservacionista capaz de manter essas perdas em níveis toleráveis (Wischmeier e Smith, 1978). Este modelo abrange os diversos fatores que podem influenciar a erosão hídrica, sendo expresso pela equação A = R.K.L.S.C.P, onde A representa as perdas médias anuais de solo $\left(\mathrm{Mg} \mathrm{ha}^{-1} \mathrm{ano}^{-1}\right)$, $\mathrm{R}$ é o índice de erosividade da chuva, $\mathrm{K}$ é o fator erodibilidade do solo, $\mathrm{L}$ o fator comprimento de rampa, $\mathrm{S}$ a declividade do terreno, $\mathrm{C}$ o fator uso, manejo e cobertura do solo e $\mathrm{P}$ o fator práticas conservacionistas de suporte do solo (Dias e Silva, 2003).

A definição do fator $\mathrm{R}$, objeto principal deste trabalho, se dá pelo cálculo do índice de erosividade das chuvas $\left(\mathrm{EI}_{30}\right)$, o qual representa a capacidade potencial da chuva em provocar o processo de erosão do solo, e é resultado da multiplicação de dois parâmetros específicos 
das precipitações erosivas de um dado local: energia cinética total da chuva (E) e intensidade máxima em 30 min $\left(\mathrm{I}_{30}\right)$. A média anual desse índice, obtida na maior série de dados de precipitação disponível, representa o fator R da área de estudo (Bazzano et al., 2010). Este parâmetro, desenvolvido nos EUA (Wischmeier e Smith, 1978), tem sido bastante aplicado em regiões tropicais e subtropicais, a exemplo do Brasil nos trabalhos de Oliveira Jr. e Medina (1990) no estado do Amazonas, Dias e Silva (2003) no Ceará, Maques et al. (1997) em Minas Gerais, Roque et al. (2001), Colodro et al. (2002) e Bertoni e Lombardi Neto (1990) em São Paulo, Hickmann et al. (2008) no Rio Grande do Sul, entre vários outros.

A determinação da erosividade da chuva possibilita identificar, durante o ano, os meses nos quais há maior risco de perda de solo e água, informação que tem papel fundamental no planejamento conservacionista urbano e rural em épocas de maior capacidade erosiva das chuvas (Wischmeier e Smith, 1978; Bertoni e Lombardi Neto, 1993; Silva et al., 2010).

Tendo em vista ser a chuva um dos principais agentes ativos no processo de erosão hídrica, é fundamental avaliar a resposta do solo às diferentes precipitações, tanto em função do volume precipitado quanto pela característica do evento. Nesse sentido, o potencial erosivo da chuva é quantificado a partir de suas características, sendo o índice de erosividade um dos mais utilizados, essencial para os estudos de perda de solo (Carvalho et al., 2009). Apesar da chuva não ser o único fator que influencia no potencial erosivo de um ambiente, na carência de outras informações e na necessidade de se avaliar os processos erosivos em dadas regiões, esta análise da erosividade da chuva é importante para gerar conhecimento e informações para áreas críticas.

No estado do Pará, o município de Rondon do Pará, localizado no sudeste paraense, tem se destacado nos últimos anos, especialmente em 2015, em função dos processos erosivos recorrentes na área urbana. Assim, este foi escolhido para a área de interesse deste estudo devido às suas peculiaridades e seu histórico de problemas associados à perda de solo.

A carência de informações sobre a erosividade da chuva na região de estudo constitui, dessa forma, um obstáculo ao planejamento de controle da erosão e ao manejo racional dos solos locais. Nesse contexto, o presente trabalho tem como objetivo determinar o fator erosividade da chuva para a área urbana do município de Rondon do Pará. Para isso, as seguintes metas devem ser alcançadas: (a) projeções da erosividade da chuva na região para os próximos 20 anos; (b) análise da distribuição anual, sazonal e mensal do índice de erosividade, e (c) correlação do índice de erosividade médio mensal com o coeficiente de chuva local.

\section{MATERIAIS E MÉTODOS}

\subsection{Caracterização da área e do material de estudo}

Localizada na região norte do território brasileiro, a área de estudo compreende a área urbana do município de Rondon do Pará/PA, localizado na latitude 446’34'S e longitude $48^{\circ} 04^{\prime} 02^{\prime}$ 'W (Figura 1). A precipitação média anual é de $1.710 \mathrm{~mm}$ e o tipo climático predominante na região é Aw, de acordo com critérios de Köppen, caracterizado por um clima tropical chuvoso. O ano hidrológico da região começa em outubro com a estação chuvosa e termina em setembro, com o fim da estiagem (CPRM, 2015).

Os processos erosivos, naturais de evolução geomorfológica na região, que está localizada no Domínio de Colinas Dissecadas e Morros Baixos e possui relevo de baixo platô, com amplitude média de 95 metros e bordas relativamente íngremes, e solos muito profundos, friáveis e com alta erodibilidade (Latossolo amarelo), se intensificam entre novembro e maio, período de grande precipitação na região, influenciados também pela concentração de águas pluviais em galerias subterrâneas que deságuam em poucos pontos na cidade (CPRM, 2015). 

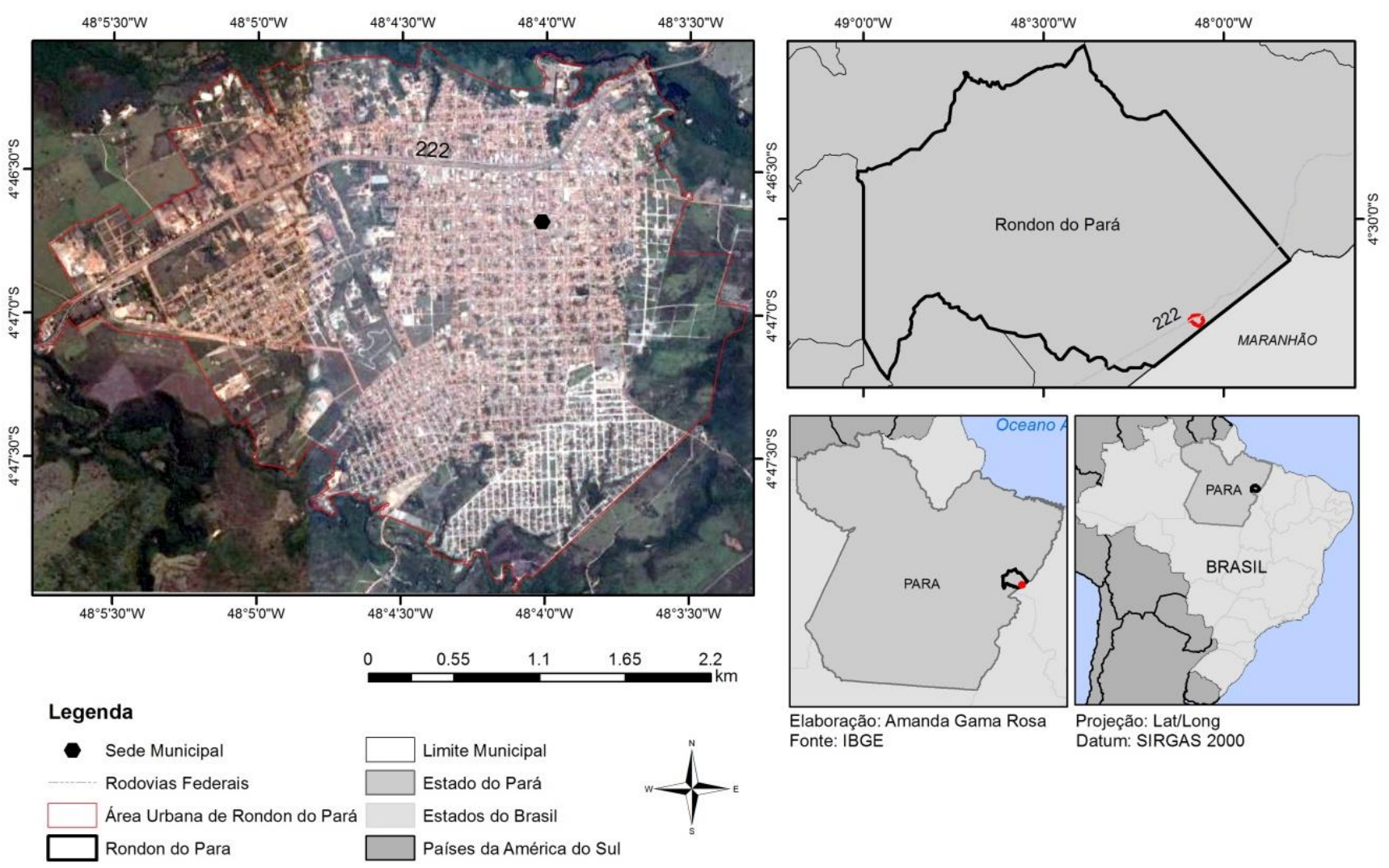

Figura 1. Localização da área de estudo.

Na metodologia foram utilizados dados observados de precipitação adquiridos a partir dos satélites CMORPH (Climate Prediction Center morphing method) para a posterior determinação da erosividade da chuva. Os dados de chuva do CMORPH (disponíveis em ftp.cpc.ncep.noaa.gov/), com séries a partir de 1998, além de fornecer dados espaciais satisfatórios com resolução espacial de $64 \mathrm{~km}^{2}$, apresenta bastante confiabilidade quantitativa, como foi comprovado em diversos estudos (Sodré e Rodrigues, 2013; Araújo e Guetter, 2007). Neste trabalho foram utilizados dados entre os anos de 1999 e 2015 provenientes de um quadrante do município que inclui a área urbana entre as latitudes $4^{\circ} \mathrm{S}$ e $5^{\circ} \mathrm{S}$ e entre as longitudes $48^{\circ} \mathrm{W}$ e $49^{\circ} \mathrm{W}$. Para esta tarefa obteve-se o auxílio do software GrADS 2.0.

Embora a maioria dos estudos faça uso de períodos de dados de precipitação mais longos, geralmente maior de 20 anos (Dias e Silva, 2003; Colodro et al., 2002; Bazzano et al., 2010; Hickmann et al., 2008; Cassol et al., 2008), conforme sugerido por Wischmeier \& Smith (1978), utilizou-se essa série de dados de 17 anos em função da indisponibilidade de dados mais antigos.

$\mathrm{Na}$ determinação da erosividade da chuva para o clima futuro, foram usados os dados fornecidos pelo Sistema de Modelagem Climática Regional - RegCM4 (Giorgi et al., 2012). A simulação climática regional na resolução de $28 \mathrm{~km}$ sobre o domínio da Amazônia foi conduzida por De Souza et al. (2016) usando o RegCM4 aninhado as condições de contorno do modelo global HADGEM2 para o cenário RCP 4.5 que é considerado como cenário intermediário de emissões globais com forçante radiativa de aproximadamente $4.5 \mathrm{~W} / \mathrm{m}^{2}$ ( $650 \mathrm{ppm}$ de $\mathrm{CO}_{2}$ ) até o ano de 2100 (Figura 2). Assim, os dados de precipitação gerados pelo RegCM4 para o quadrante da região de Rondon do Pará foram extraídos para o período de 2016 a 2035. 


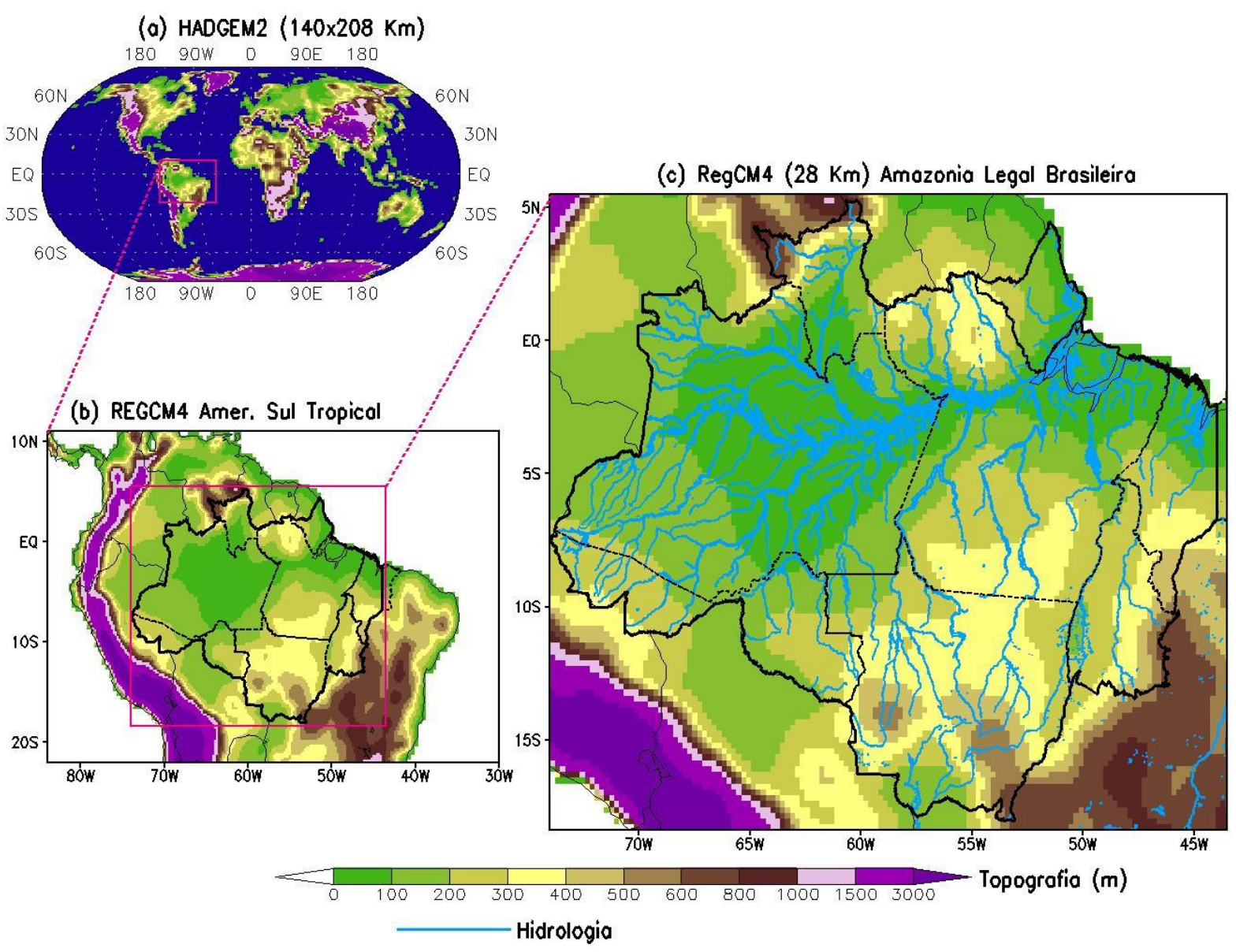

Figura 2. Domínios dos modelos: (a) global HadGEM2 (resolução 140 x 208 km) e (b) regional RegCM4 (resolução 28 x $28 \mathrm{~km}$ ) sobre a América do Sul tropical com o destaque para (c) a região da Amazônia Legal Brasileira. As cores representam a topografia (m) e as isolinhas azuis mostram a hidrologia (rios principais).

Fonte: De Souza et al. (2016).

Este Sistema de Modelagem Climática Regional utiliza dados de precipitação gerados através do sistema de análise de dados observacionais do "Climate Prediction Center" (CPC, USA). Os dados de chuva do CPC consistem de médias mensais disponíveis numa grade sobre o Brasil com resolução horizontal de $55 \mathrm{~km}$, e são baseados inteiramente nos registros das estações de superfície da rede meteorológica nacional e estadual. Os detalhes sobre a técnica de análise objetiva e interpolação empregados na geração destes dados encontram-se em Chen et al. (2008). Estudos anteriores demonstraram ótima consistência e correspondência entre os dados do CPC e dados derivados de estações convencionais individuais e estimativas de satélite sobre a região da Amazônia (Silva et al., 2007; De Souza et al., 2009).

\subsection{Determinação dos índices de erosividade}

Um dos primeiros estudos acerca da erosividade foi o realizado por Wischmeier e Smith (1958), posteriormente modificado por Foster et al. (1981), os quais propuseram um índice de erosividade da chuva denominado $\mathrm{EI}_{30}$, definido como o produto da energia cinética da chuva pela intensidade máxima ocorrida em um período de 30 minutos. Porém, em função da dificuldade de obtenção de registros e do grande trabalho no processamento dos dados, outros autores, como Silva (2004), propuseram uma metodologia que permite estimar a erosividade da chuva para cada mês usando dados diários e mensais de precipitação. 
Silva (2004) sugeriu que o país fosse dividido em oito regiões homogêneas em termos de precipitação, as quais possuiriam equações específicas para cada realidade. A área de interesse deste trabalho está incluída na região dois desta divisão, que possui método estabelecido por Morais et al. (1991) representado pela Equação 1.

$$
\mathrm{R}_{\mathrm{x}}=36,849\left(\frac{\mathrm{M}_{\mathrm{x}}^{2}}{\mathrm{P}}\right)^{1,0852}
$$

em que:

$\mathrm{Rx}=$ erosividade da chuva para cada mês;

$\mathrm{Mx}=$ precipitação média mensal; e

$\mathrm{P}=$ precipitação média anual.

Assim, foram calculados índices de erosividade para os 17 anos de dados, 1999 a 2015, gerando índices mensais, que foram somados, originando o índice de erosividade anual para a área de estudo. A erosividade prevista para os anos de 2016 a 2035 foi determinada pela mesma metodologia. $\mathrm{O}$ valor final classificou a região dentre as classes de erosividade de acordo com a Tabela 1 .

Tabela 1. Classificação do Índice de Erosividade Anual (R).

\begin{tabular}{cl}
\hline $\begin{array}{c}\text { Erosividade } \\
\left(\mathrm{MJ} \mathrm{mm} \mathrm{ano}^{-1} \mathrm{ha}^{-1} \mathrm{~h}^{-1}\right)\end{array}$ & Classe de Erosividade \\
\hline $\mathrm{R} \leq 2452$ & Baixa erosividade \\
$2452<\mathrm{R} \leq 4905$ & Média erosividade \\
$4905<\mathrm{R} \leq 7357$ & Média-alta erosividade \\
$7357<\mathrm{R} \leq 9810$ & Alta erosividade \\
$\mathrm{R}>9810$ & Muito Alta erosividade \\
\hline
\end{tabular}

Fonte: Carvalho (1994), modificado de Foster et al. (1981).

\subsection{Probabilidade de ocorrência e período de retorno do índice de erosividade}

Nas análises de probabilidade de ocorrência e do período de retorno do índice de erosividade determinados para os anos de 1999 a 2015, foram usadas a lei de probabilidade logarítmica e a teoria de valores extremos (Schwab et al., 1981). O período de retorno e a probabilidade de ocorrência foram obtidos pelas Equações 2 e 3.

$$
\mathrm{T}=(\mathrm{N}+1) / \mathrm{m}
$$

em que:

T é o período de retorno, no qual o índice de erosividade é igualado ou superado;

$\mathrm{N}$ é o número de anos de registro de dados, e

m é o número de ordem do índice de erosividade, quando a série de dados de erosividade é colocada em ordem decrescente de magnitutde.

$$
\operatorname{Pr}=100 / \mathrm{T}
$$

\section{IPABH}

Rev. Ambient. Água vol. 11 n. 4 Taubaté - Oct. / Dec. 2016 
em que:

Pr é a probabilidade de ocorrência, e

T é o tempo de retorno.

Utilizou-se o programa OriginPro 8.0 como auxílio na confecção do gráfico da plotagem dos valores determinados das probabilidades de ocorrência, dos períodos de retorno e da curva de distribuição de probabilidade.

\subsection{Distribuição anual e mensal da percentagem acumulada da erosividade}

Os valores dos índices de erosividade médios mensais foram divididos pelo seu valor médio anual, obtendo-se os respectivos valores relativos mensais. Esses valores, modificados para percentagens, representam a porcentagem acumulada da erosividade para cada mês do ano, possibilitando a análise da distribuição da erosividade ao longo dos períodos.

\subsection{Correlação entre a precipitação e o índice de erosividade}

Utilizando os dados pluviométricos de 1999 a 2015, e de 2016 a 2035, para cada mês do ano, foi calculado o coeficiente de chuva, por meio do método proposto por Lombardi Neto (1977), cuja expressão é dada pela Equação 4.

$$
\mathrm{Rc}=\mathrm{Pm}^{2} / \mathrm{Pa}
$$

em que:

Rc é o coeficiente de chuva em mm;

Pm é a precipitação média mensal em mm, e

$\mathrm{Pa}$ é a precipitação média anual.

Os valores dos coeficientes de chuva foram correlacionados com os valores de erosividades por meio de regressão, visando identificar relação entre a precipitação e a ocorrência de processos erosivos.

\section{RESULTADOS E DISCUSSÃO}

O fator erosividade da chuva (R) determinado para Rondon do Pará (PA), com base nos dados de precipitação observados (1999 a 2015), foi de $16.390 \mathrm{MJ} \mathrm{mm} \mathrm{ha-1} \mathrm{h}^{-1}$ ano $^{-1}$, com desvio padrão de 3.640 e coeficiente de variação de $22 \%$, classificando a região em área de muito alta erosividade. Com base nos dados de precipitação por modelagem, nos anos de 2016 a 2035, obteve-se um fator de erosividade de $13.038 \mathrm{MJ} \mathrm{mm} \mathrm{ha}^{-1} \mathrm{~h}^{-1} \mathrm{ano}^{-1}$, com desvio padrão de 2.239 e coeficiente de variação de $17 \%$, mantendo a classificação de muito alta erosividade (Tabela 2 e Figura 3). Estes valores do fator erosividade encontrados enquadram-se na faixa de variação de 3.116 a $20.035 \mathrm{MJ} \mathrm{mm} \mathrm{ha}^{-1} \mathrm{~h}^{-1}$ ano $^{-1}$, encontrada por Silva (2004) através do mapa de erosividade da chuva para o Brasil.

A variação observada nas curvas de erosividade anual nos dois períodos (Figura 3) se dá em função das pequenas distinções na estimativa de dados de precipitação nas duas séries, sendo uma série originada de dados observados (CMORPH) e outra resultante de dados de modelagem (RegCM4).

Os valores dos fatores de erosividade da chuva encontrados para Rondon do Pará foram significativamente superiores aos encontrados para outras regiões do Brasil, como o encontrado para Teodoro Sampaio (SP) (7.172 $\mathrm{MJ} \mathrm{mm} \mathrm{ha}^{-1} \mathrm{~h}^{-1}$ ano $^{-1}$ ) por Colodro et al. (2002), para Rio Grande (RS) (5.135 MJ mm ha ${ }^{-1} \mathrm{~h}^{-1}$ ano $^{-1}$ ) por Bazzano et al. (2010), para 
Barranquinho (MT) (8.493 MJ mm ha ${ }^{-1} \mathrm{~h}^{-1}$ ano $^{-1}$ ) por Morais et al. (1991), para Fortaleza (CE) (6.774 MJ mm ha $\mathrm{h}^{-1} \mathrm{ano}^{-1}$ ) por Dias \& Silva (2003), para Goiânia (GO) (8.355 MJ mm ha $\mathrm{ha}^{-1}$ ano $^{-1}$ ) por Silva et al. (1997), e para Uruguaiana (RS) (8.875 MJ mm ha ${ }^{-1} \mathrm{~h}^{-1}$ ano $^{-1}$ ), por Hickmann (2008). Os fatores de erosividade apresentados nos trabalhos citados, possivelmente, se mostram discrepantes, comparados ao valor encontrado neste trabalho, devido à grande distinção climática com a área de estudo deste trabalho. Entretanto, não há grande disponibilidade de estudos de erosividade para a região norte do país, dificultando a discussão dos resultados com trabalhos semelhantes na região.

Tabela 2. Distribuição média mensal da precipitação, da erosividade absoluta e relativa e do coeficiente de chuva de Rondon do Pará (PA), nos períodos de 1999 a 2015, e 2016 a 2035.

\begin{tabular}{|c|c|c|c|c|c|}
\hline \multicolumn{6}{|c|}{ Total Mensal } \\
\hline Ano & Mês & $\begin{array}{l}\text { Prp } \\
(\mathrm{mm})\end{array}$ & $\begin{array}{c}\text { Erosividade } \\
\left(\mathrm{MJ} \mathrm{mm} \mathrm{ano} \mathrm{ma}^{-1} \mathrm{~h}^{-1}\right)\end{array}$ & $\begin{array}{l}\text { Erosividade } \\
\text { Relativa (\%) }\end{array}$ & $\begin{array}{l}\text { Coef. de Chuva } \\
\text { - Rc (mm) }\end{array}$ \\
\hline \multirow{12}{*}{1999 a 2015} & Jan & 245,94 & 1952,60 & 11,91 & 35,36 \\
\hline & Fev & 315,82 & 3867,55 & 23,60 & 58,31 \\
\hline & Mar & 340,41 & 4218,22 & 25,74 & 67,75 \\
\hline & Abr & 294,65 & 3720,82 & 22,70 & 50,75 \\
\hline & Mai & 122,53 & 711,99 & 4,34 & 8,78 \\
\hline & Jun & 21,88 & 56,96 & 0,35 & 0,28 \\
\hline & Jul & 13,88 & 11,85 & 0,07 & 0,11 \\
\hline & Ago & 7,06 & 5,10 & 0,03 & 0,03 \\
\hline & Set & 18,88 & 34,03 & 0,21 & 0,21 \\
\hline & Out & 54,65 & 156,71 & 0,96 & 1,75 \\
\hline & Nov & 132,71 & 768,52 & 4,69 & 10,30 \\
\hline & Dez & 142,12 & 885,69 & 5,40 & 11,81 \\
\hline \multirow[t]{6}{*}{ Total anual } & & 1710,53 & 16390,04 & 100,00 & - \\
\hline & Jan & 262,57 & 2228,66 & 17,09 & 40,80 \\
\hline & $\mathrm{Fev}$ & 265,48 & 2165,12 & 16,61 & 41,71 \\
\hline & Mar & 372,16 & 4596,90 & 35,26 & 81,97 \\
\hline & Abr & 256,05 & 2186,98 & 16,77 & 38,80 \\
\hline & Mai & 145,24 & 652,25 & 5,00 & 12,48 \\
\hline \multirow[t]{7}{*}{2016 a 2035} & Jun & 16,35 & 12,03 & 0,09 & 0,16 \\
\hline & Jul & 17,83 & 10,55 & 0,08 & 0,19 \\
\hline & Ago & 13,80 & 6,33 & 0,05 & 0,11 \\
\hline & Set & 25,80 & 14,62 & 0,11 & 0,39 \\
\hline & Out & 46,50 & 49,22 & 0,38 & 1,28 \\
\hline & Nov & 108 & 313,90 & 2,41 & 6,90 \\
\hline & Dez & 159,96 & 801,46 & 6,15 & 15,14 \\
\hline Total anual & & 1689,72 & 13038,01 & 100,00 & - \\
\hline
\end{tabular}




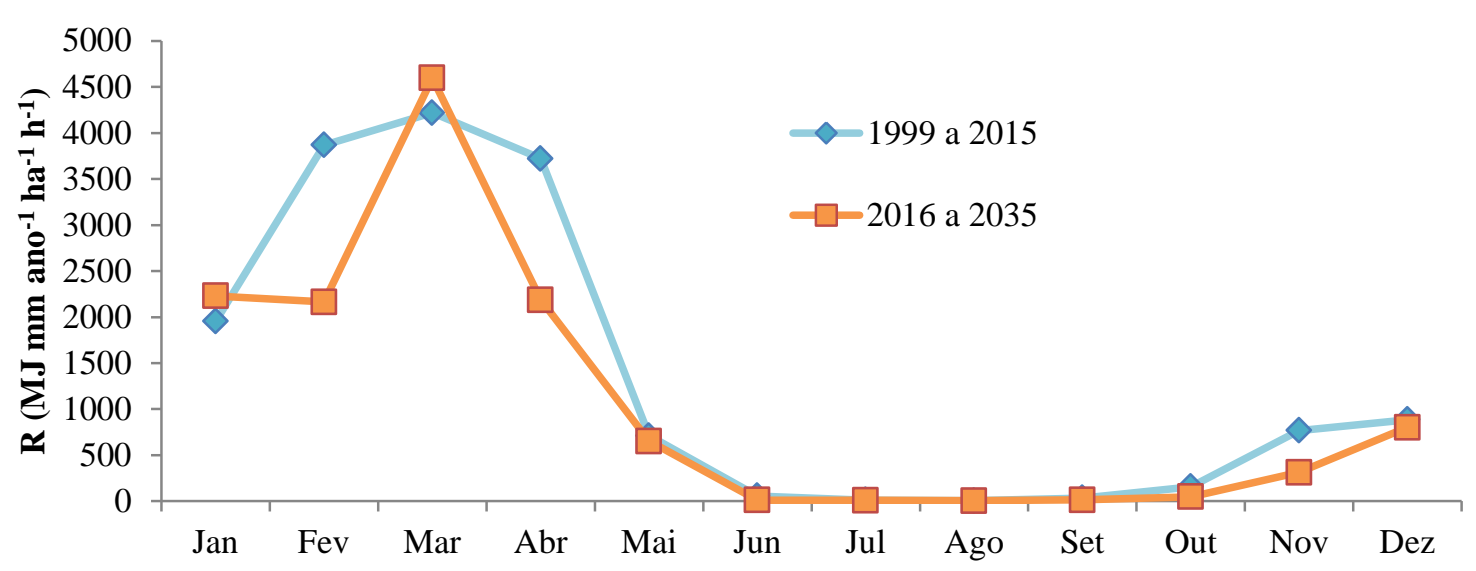

Figura 3. Distribuição do fator erosividade (R) médio anual para os períodos de 1999 a 2015 (dados observados) e 2016 a 2035 (dados de modelagem).

Valores de erosividade da chuva semelhantes foram encontrados por Oliveira Jr. e Medina (1990) em Manaus (AM), com índice de 14.129 $\mathrm{MJ} \mathrm{mm} \mathrm{ha}^{-1} \mathrm{~h}^{-1} \mathrm{ano}^{-1}$, e por Oliveira Jr. (1996) em Conceição do Araguaia (PA), com índice de $11.487 \mathrm{MJ} \mathrm{mm} \mathrm{ha}^{-1} \mathrm{~h}^{-1}$ ano ${ }^{-1}$. O valor mais próximo era esperado em função da semelhança da distribuição anual e das características da precipitação na região norte. Valores próximos foram encontrados também por Silva et al. (2010) para São Domingos do Prata (MG) (13.145 MJ mm ha ${ }^{-1} \mathrm{~h}^{-1} \mathrm{ano}^{-1}$ ), Santo Antônio do Itambé (MG) (15.280 MJ mm ha' ${ }^{-1} \mathrm{~h}^{-1} \mathrm{ano}^{-1}$ ) e Belo Oriente (MG) (12.919 MJ mm ha $\left.{ }^{-1} \mathrm{~h}^{-1} \mathrm{ano}^{-1}\right)$.

Considerando os valores relativos da erosividade mensal entre os anos de 1999 a 2015, verifica-se que no semestre de novembro a abril ocorre $94,04 \%$ da erosividade anual, sendo o trimestre fevereiro-março-abril o de maior recorrência, com 72,04\% da erosividade anual, valor compatível com a distribuição da precipitação na região, indicando que neste período é provável que tenha ocorrido a maior parte das perdas anuais de solo por erosão em Rondon do Pará. Tal comportamento da distribuição da erosividade também é observado entre os anos 2016 e 2035, com os dados de modelagem climática (Tabela 2). Para esta segunda série de dados, o semestre de maior ocorrência da erosividade anual foi de dezembro a maio, com $96,88 \%$, sendo o quadrimestre janeiro-fevereiro-março-abril o de maior destaque, ocorrendo $85,73 \%$ da erosividade anual. Embora a variação nos valores mensais da precipitação e suas características possam explicar grande parte das variações na erosividade (Bazzano et al., 2010), é importante destacar que estes não são os únicos fatores influentes dos processos erosivos, a exemplo da geologia, pedologia, relevo e o uso do solo (Silva e Machado, 2014).

Outros trabalhos na literatura elaboraram uma análise da erosividade relativa, como Colodro et al. (2002) para Teodoro Sampaio (SP), Roque et al. (2001) para Pirajú (SP), Lombardi Neto (1977) para Campinas (SP), Pereira (1983) para Piracicaba (SP), entre outros. Esses autores definiram como o semestre de maior potencial de erosividade, o de outubro a março, coerente para o estado de São Paulo, enquanto que para Rondon do Pará (PA), este foi de novembro a abril. Apesar da diferença de um mês no intervalo do semestre com maior potencial de erosividade anual, é válida uma comparação entre os seus resultados, a fim de discutir o comportamento da erosividade anual do município de Rondon do Pará. Em termos absolutos, o valor de erosividade para o semestre de maior potencial foi de 15.413, 6.047, 5.545, 5.307 e 4.933 MJ mm ha ${ }^{-1} \mathrm{~h}^{-1}$ ano $^{-1}$, respectivamente, para Rondon do Pará (1999 a 2015), Campinas, Pirajú, Teodoro Sampaio e Piracicaba. Em termos relativos, a erosividade foi de 94,04; 90,7; 86,1; 78,5 e 74,0\%, para Rondon do Pará, Campinas, Piracicaba, Pirajú e Teodoro Sampaio, respectivamente. Com base nesta análise, pode-se concluir que tanto em termos absolutos como relativos eram prováveis maiores perdas de solo por erosão em 
Rondon do Pará quando comparadas às dos outros municípios em questão, o que indica maiores necessidades de cuidados com a proteção do solo.

A Figura 4 indica haver uma conformidade entre as distribuições médias mensais do fator erosividade e precipitação, entre os anos de 1999 a 2015, do município de Rondon do Pará. Observa-se que a erosividade média anual para a área de estudo é de $16.390 \mathrm{MJ} \mathrm{mm} \mathrm{ha}^{-1}$ $\mathrm{h}^{-1}$ ano ${ }^{-1}$, para uma precipitação média de $1710,53 \mathrm{~mm}$ ano ${ }^{-1}$, estando os meses com maiores precipitações associados com os meses de maior erosividade, reforçando a ideia do efeito preponderante da intensidade da precipitação em caracterizar o potencial erosivo. $\mathrm{O}$ mesmo comportamento é verificado na série de dados de 2016 a 2035. Esta harmonia entre a precipitação e a erosividade pode ser encontrada em outros trabalhos, como o de Oliveira Jr. (1996) para Conceição do Araguaia (PA), de Colodro et al. (2002) para Teodoro Sampaio (SP), de Morais et al. (1991) para Cárceres (MT) e Corixa (MT), de Roque et al. (2001) para Piraju (SP), e de Hickmann et al. (2008) para Uruguaiana (RS), e de Silva et al. (2010) para a região centro-leste do Estado de Minas Gerais. Bazzano et al. (2010), na análise da erosividade em Rio Grande (RS), encontraram um comportamento distinto, onde em meses de alta precipitação (junho, julho e agosto) foram identificadas baixos índices de erosividade mensais, comparados ao resto do ano.
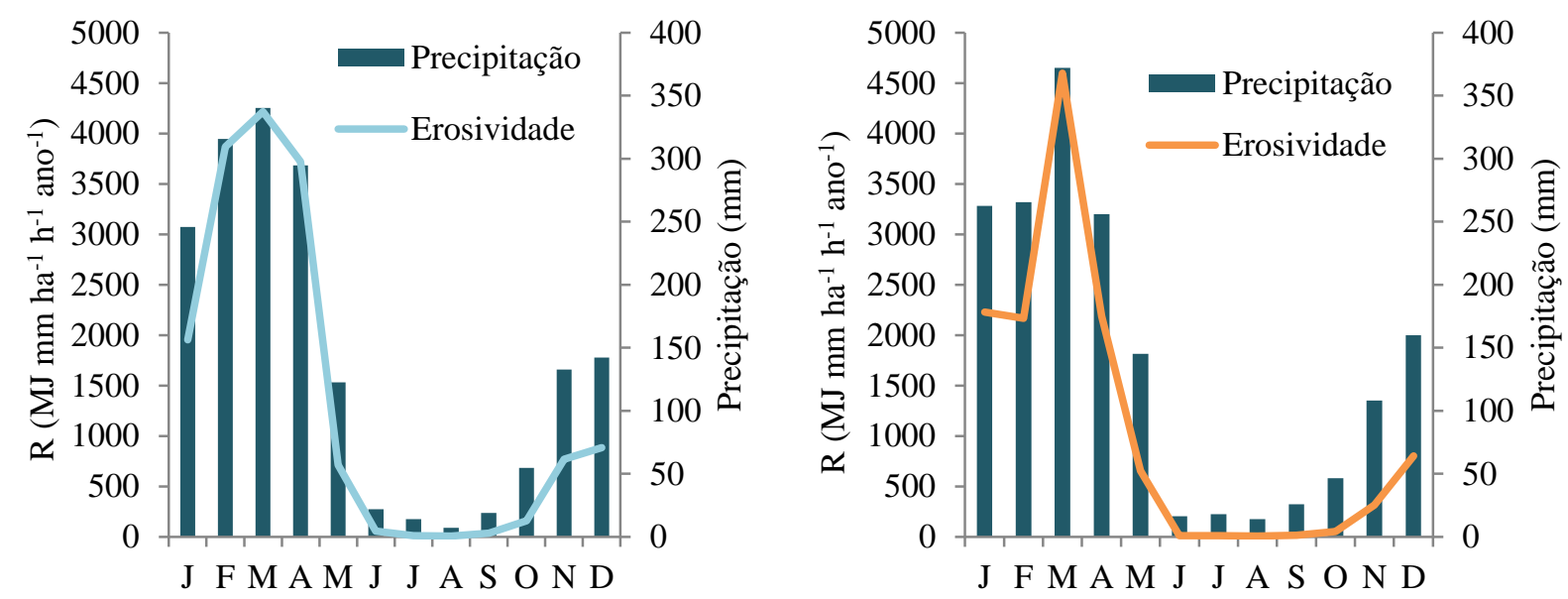

Figura 4. Distribuição do fator erosividade (R) e da precipitação médias anuais de Rondon do Pará (PA) nos períodos de 1999 a 2015 (à esquerda), e 2016 a 2035 (à direita).

Os valores do período de retorno e da probabilidade de ocorrência determinados para o maior parâmetro de erosividade anual observado (23.880 MJ mm ha ${ }^{-1} \mathrm{~h}^{-1}$ ano $^{-1}$, em 2002) foram de 18 anos e 5,6\%, respectivamente (Tabela 3). Os períodos de retorno e probabilidade de ocorrência para o menor valor de erosividade (10.110 $\mathrm{MJ} \mathrm{mm} \mathrm{ha}^{-1} \mathrm{~h}^{-1} \mathrm{ano}^{-1}$, em 2012) foram, respectivamente, 1,1 anos e 94,4\%. Assim, espera-se que ocorra na área de estudo, com uma probabilidade de $5,6 \%$, um valor de erosividade anual igual ou superior a $23.880 \mathrm{MJ}$ $\mathrm{mm} \mathrm{ha}{ }^{-1} \mathrm{~h}^{-1}$ ano $^{-1}$ pelo menos uma vez a cada 18 anos, e que, com uma probabilidade de $94,4 \%$, ocorra um valor de erosividade igual ou superior a $10.110 \mathrm{MJ} \mathrm{mm} \mathrm{ha} \mathrm{h}^{-1} \mathrm{ano}^{-1}$ pelo menos uma vez a cada 1,1 ano, em ambos os casos, classificando a região como de muito alta erosividade. Para a análise do período de retorno e da probabilidade de ocorrência foram utilizados apenas os dados de 1999 a 2015, devido serem resultantes de séries observadas.

Para um período de análise de 20 anos, em Fortaleza (CE), Dias e Silva (2003) encontraram valor máximo (12.881 $\left.\mathrm{MJ} \mathrm{mm} \mathrm{ha}^{-1} \mathrm{~h}^{-1} \mathrm{ano}^{-1}\right)$ e mínimo $\left(2.237 \mathrm{MJ} \mathrm{mm} \mathrm{ha} \mathrm{m}^{-1}\right.$ ano $^{-1}$ ) da erosividade anual, com períodos de retorno de 21 e 1,05 anos, e probabilidades de ocorrência de 4,8\% e 95,2\%, respectivamente. Para um período de 23 anos de dados, Roque et al. (2001), em Piraju (SP), encontraram um valor máximo de $12.940 \mathrm{MJ} \mathrm{mm} \mathrm{ha}^{-1} \mathrm{~h}^{-1} \mathrm{ano}^{-1} \mathrm{e}$ 
mínimo de $3.624 \mathrm{MJ} \mathrm{mm} \mathrm{ha}{ }^{-1} \mathrm{~h}^{-1}$ ano $^{-1}$ de erosividade anual, com período de retorno e probabilidades de ocorrência iguais a 24 anos e 4,2\% para o máximo, e 1,04 anos e 96,2\% para o mínimo. Seguramente, tanto os períodos de estudo diferentes da análise como as diferenças climáticas entre o Pará, o Ceará e São Paulo, condicionaram valores superiores de erosividade encontrada para o município de Rondon do Pará (PA).

O período de retorno do fator erosividade da chuva $(\mathrm{R})$ do município de Rondon do Pará (16.390 MJ mm ha ${ }^{-1} \mathrm{~h}^{-1}$ ano $^{-1}$ ) foi de aproximadamente 2,1 anos, equivalentes a uma probabilidade de ocorrência de 47\% (valores obtidos da Figura 5). Esse valor foi próximo daqueles obtidos para os fatores R de Teodoro Sampaio (SP) (2,33 anos) por Colodro et al. (2002), de Campinas (SP) (2,1 anos) por Lombardi Neto (1977), de Piraju (SP) (2,3 anos) por Roque et al. (2001), de Piracicaba (SP) (2,1 anos) por Pereira (1983), de Fortaleza (CE) (2,2 anos) por Dias e Silva (2003), e de Conceição do Araguaia (PA) (2,7 anos) por Oliveira Jr. (1996). Conclui-se, portanto, ser possível ocorrer no município, em uma probabilidade de $47 \%$ um valor de erosividade anual igual ou superior ao fator $\mathrm{R}$ calculado, pelo menos uma vez a cada 2,1 anos. A leitura dessa curva (Figura 5) permite estimar os períodos de retorno e probabilidades de ocorrência para diferentes valores de erosividade.

Tabela 3. Probabilidade de ocorrência e período de retorno dos valores anuais de erosividade de Rondon do Pará (PA) no período de 1999 a 2015.

\begin{tabular}{ccccc}
\hline Ano & $\begin{array}{c}\text { Erosividade } \\
\left(\mathrm{MJ} \mathrm{mm} \mathrm{ha}^{-1} \mathrm{~h}^{-1} \mathrm{ano}^{-1}\right)\end{array}$ & $\begin{array}{c}\text { Número de } \\
\text { Ordem, } \mathrm{m}\end{array}$ & $\begin{array}{c}\text { Período de Retorno, } \\
\mathrm{T}(\mathrm{anos})\end{array}$ & $\begin{array}{c}\text { Probabilidade, } \\
\text { Pr }(\%)\end{array}$ \\
\hline 2002 & 23.880 & 1 & 18,0 & 5,6 \\
1999 & 20.677 & 2 & 9,0 & 11,1 \\
2009 & 20.513 & 3 & 6,0 & 16,7 \\
2014 & 19.492 & 4 & 4,5 & 22,2 \\
2015 & 18.522 & 5 & 3,6 & 27,8 \\
2007 & 18.089 & 6 & 3,0 & 33,3 \\
2006 & 17.648 & 7 & 2,6 & 38,9 \\
2001 & 17.036 & 8 & 2,3 & 44,4 \\
2005 & 15.955 & 9 & 2,0 & 50,0 \\
2003 & 15.458 & 10 & 1,8 & 55,6 \\
2008 & 15.402 & 11 & 1,6 & 61,1 \\
2004 & 14.737 & 12 & 1,5 & 66,7 \\
2011 & 14.516 & 13 & 1,4 & 72,2 \\
2013 & 12.639 & 14 & 1,3 & 77,8 \\
2010 & 12.608 & 15 & 1,2 & 83,3 \\
2000 & 11.350 & 16 & 1,1 & 88,9 \\
2012 & 10.110 & 17 & 1,1 & 94,4 \\
DP & 3.640 & & & \\
CV \% & 22 & & & \\
\hline
\end{tabular}




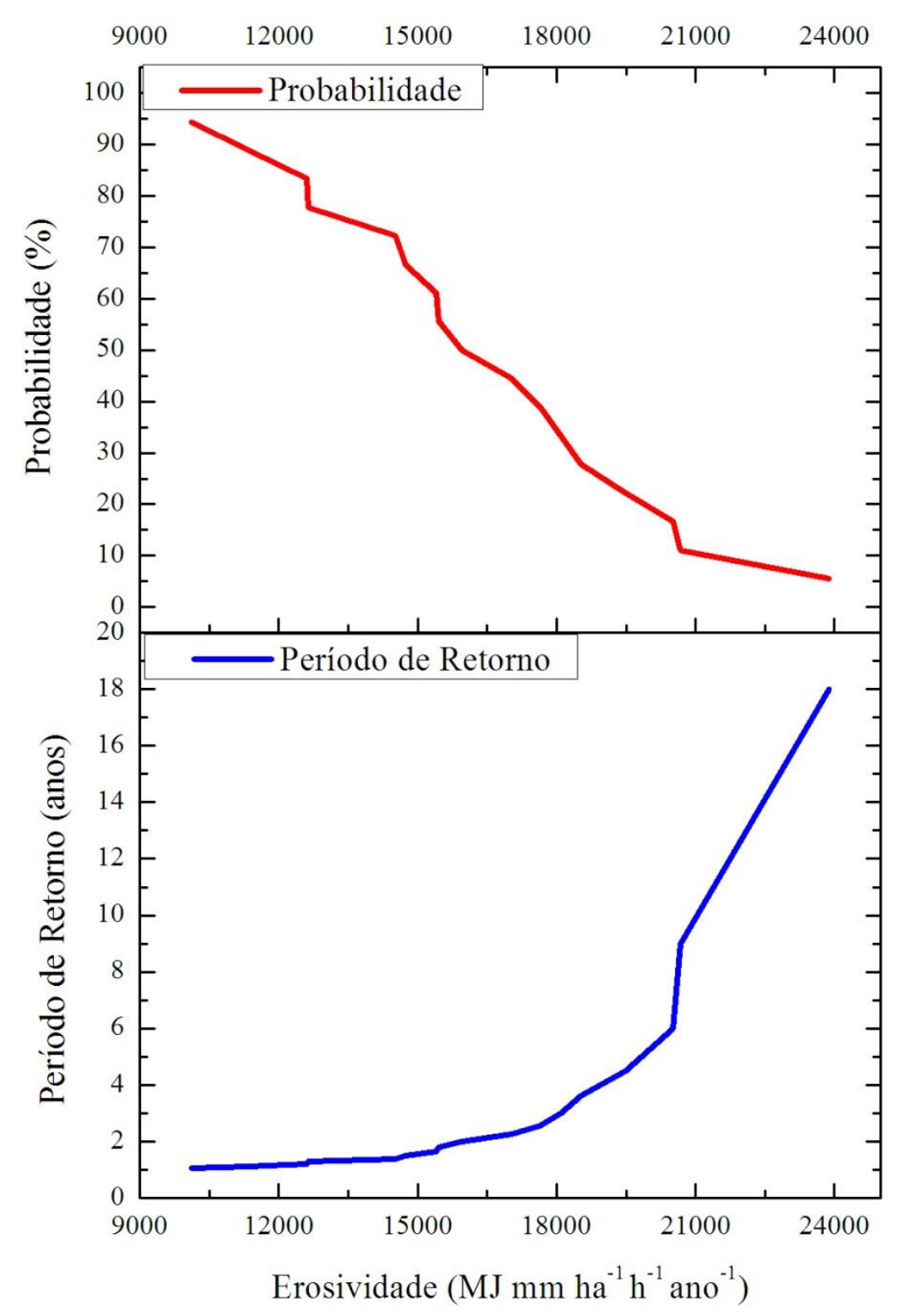

Figura 5. Curva de probabilidade de ocorrência e período de retorno da erosividade anual de Rondon do Pará (PA) no período de 1999 a 2015.

A Figura 6 apresenta a curva de regressão entre o índice de erosividade médio mensal e o coeficiente de chuva para Rondon do Pará para a série de dados observados (1999 a 2015) e para a série de dados oriundos de modelagem (2016 a 2015).

Rondon do Pará apresentou elevada correlação entre o fator erosividade médio mensal e o coeficiente de chuva. Isto indica que a erosividade mensal das chuvas no município pode ser estimada utilizando dados de precipitação. O modelo matemático que apresentou a melhor correlação foi o de potência para o período de 1999 a 2015, $\left(\mathrm{r}^{2}=0,993\right)$, conforme a equação (Figura 6), concordando com os resultados de Roque et al. (2001) para Piraju (SP), de Lombardi Neto (1977) para Campinas (SP), de Pereira (1983) para Piracicaba, dentre outros. Por outro lado, contrastou com os dados de Colodro et al. (2002) e Rufino et al. (1993), nos quais a relação linear apresentou maior correlação, e com os dados de Hickmann et al. (2008), 
onde a relação quadrática apresentou melhor correlação. Para o período de 2016 a 2035, o modelo matemático que apresentou melhor correlação foi o de polinômio $\left(\mathrm{r}^{2}=0,9991\right)$, de acordo com a equação (Figura 6), embora a relação linear também tenha apresentado elevada correlação entre os dados.
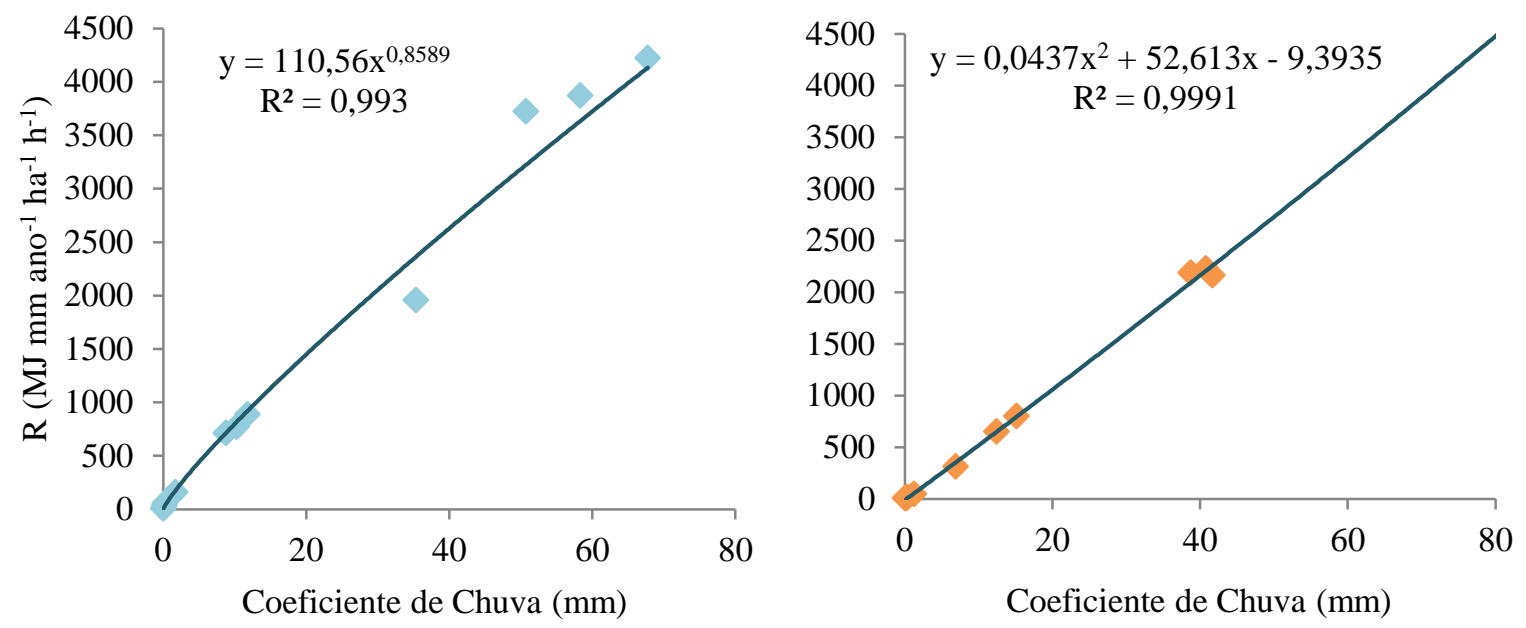

Figura 6. Curva de regressão entre a erosividade média mensal (R) e o coeficiente de chuva de Rondon do Pará (PA) nos períodos de 1999 a 2015 (a esquerda), e de 2016 a 2035 (a direita).

Fonte: Autores.

\section{CONCLUSÕES}

Os fatores erosividade da chuva para o município de Rondon do Pará (PA) foram de 16.390 MJ mm ha ${ }^{-1} \mathrm{~h}^{-1}$ ano $^{-1}$ no período de 1999 a 2015, e $13.038 \mathrm{MJ} \mathrm{mm} \mathrm{ha}^{-1} \mathrm{~h}^{-1}$ ano $^{-1}$ no período de 2016 a 2035. O fator $16.390 \mathrm{MJ} \mathrm{mm} \mathrm{ha}^{-1} \mathrm{~h}^{-1} \mathrm{ano}^{-1}$, que revela uma probabilidade de ocorrência de $47 \%$, pode ser igualado ou superado pelo menos uma vez a cada 2,1 anos. Os índices de erosividade anual foram considerados muito altos, estabelecendo cenários críticos para o planejamento de práticas conservacionistas do solo e da água.

Nos meses de fevereiro, março e abril, observou-se uma distribuição de 72,04\% do total na erosividade anual para o período de 1999 a 2015, indicando que, neste período, era provável que ocorresse a maior parte das perdas anuais de solo por erosão. Para o período de dados de 2016 a 2035, os meses de janeiro, fevereiro, março e abril foram os que mais se destacaram na distribuição da erosividade, ocorrendo $85,73 \%$ do total na erosividade anual.

O modelo matemático que apresentou a melhor correlação entre a erosividade média mensal e o coeficiente de chuva foi o de potência para os anos de 1999 a 2015 e o de polinômio para os anos de 2016 a 2035.

\section{REFERENCIAS}

ARAÚJO, N. A.; GUETTER, A. K. Validação da chuva estimada por satélite "CMORPH" na modelagem hidrológica do Alto Iguaçú. RBRH, v. 12, n. 3, p. 189-198, 2007.

BAZZANO, M. G. P.; ELTZ, F. L. F.; CASSOL, E. A. Erosividade e características hidrológicas das chuvas de Rio Grande (RS). R Bras Ci Solo, v. 34, p. 235-244, 2010. http://hdl.handle.net/10183/80298 
BERTONI, J.; LOMBARDI NETO, F. Conservação do solo. São Paulo: Ícone; 1990.

BROWN, L. R. The global loss of topsoil. J Soil Water Conserv, v. 39, p. 162-165, 1984.

CARVAlHO, D. F.; CRUZ, E. S.; PINTO, M. F.; SILVA, L. D. B.; GUERRA, J. G. M. Características da chuva e perdas por erosão sob diferentes práticas de manejo do solo. R Bras Eng Agríc Ambiental, v. 13, n. 1, p. 3-9, 2009.

CARVAlHO, N. O. Hidrossedimentologia Prática. Rio de Janeiro: CPRM, 1994.

CASSOL, E. A.; ELTZ, F. L. F.; MARTINS, D.; LEMOS, A. M.; LIMA, V. S.; BUENO, A. C. Erosividade, padrões hidrológicos, período de retorno e probabilidade de ocorrência das chuvas em São Borja, RS. R Bras Ci Solo, v. 32, p. 1239-1251, 2008. http://hdl.handle.net/10183/79905

CENTRO UNIVERSITÁRIO DE ESTUDOS E PESQUISAS SOBRE DESASTRES CEPED. Atlas brasileiro de desastres naturais: 1991-2012. Volume Pará. 2. ed. rev., ampl. Florianópolis: CEPED UFSC, 2013.

CHEN, M.; SHI, W.; XIE, P. Assessing objective techniques for gauge-based analyses of global daily precipitation. J Geophys Research, v. 113, p. D04110, 2008. http://dx.doi.org/10.1029/2007JD009132

COLODRO, G.; CARVALHO, M. P.; ROQUE, C. G.; PRADO, R. M. Erosividade da Chuva: Distribuição e correlação com a precipitação pluviométrica de Teodoro Sampaio (SP). R Bras Ci Solo, v. 26, p. 809-818, 2002. http://dx.doi.org/10.1590/S010006832002000300027

COMPANHIA DE PESQUISA DE RECURSOS MINERAIS - CPRM. Ação emergencial para delimitação de áreas em alto e muito alto risco a enchentes e movimentos de massa - Rondon do Pará, Pará. Belém, 2015.

DE SOUZA, E. B.; CARMO, A. M. C.; MORAES, B. C.; NACIF, A.; FERREIRA, D. B. S.; ROCHA, E. J. P. et al. Sazonalidade da precipitação sobre a Amazônia Legal Brasileira: clima atual e projeções futuras usando o modelo RegCM4. R Brasil Climatologia, 2016 (in press). http://dx.doi.org/10.5380/abclima.v18i0.43711

DE SOUZA, E. B.; LOPES, M. N. G.; ROCHA, E. J. P.; SOUZA, J. R. S.; CUNHA, A. C.; SILVA, R. R. et al. Precipitação climatológica sobre a Amazônia oriental durante o período chuvoso: observações e simulações regionais com o RegCM3. R Bras Meteorol, v. 24, n. 2, p. 111-124, 2009.

http://repositorio.ufpa.br/jspui/handle/2011/2190

DIAS, A. S.; SILVA, J. R. C. A Erosividade das chuvas em Fortaleza (CE). I - distribuição, probabilidade de ocorrência e período de retorno - primeira aproximação. R Bras Ci Solo, v. 27, p. 335-345, 2003.

FOSTER, G. R.; MCCOOL, D. K.; RENARD, K. G.; MOLDENHAUER, W. C. Conversion of the universal soil loss equation to SI units. J Soil Water Conserv, v. 36, p. 355-359, 1981.

GIORGI, F.; COPPOLA, E.; SOLMON, F.; MARIOTTI, L.; SYLLA, M..; BI, X. et al. RegCM4: model description and preliminary tests over multiple CORDEX domains. Climate Research, v. 52, p. 7-29, 2012. http://dx.doi.org/10.3354/cr01018 
HICKMANN, C.; ELTZ, F. L. F.; CASSOL, E. A.; COGO, C. M. Erosividade das chuvas em Uruguaiana, RS, determinada pelo Índice $\mathrm{EI}_{30}$, com base no período de 1963 a 1991 . R Bras Ci Solo, v. 32, p. 825-831, 2008. http://hdl.handle.net/10183/107075

LOMBARDI NETO, F. Rainfall erosivity - Its distribution and relationship with soil loss at Campinas, Brasil. 1977. 53f. Dissertação (Mestrado em Agronomy) - Purdue University, West Lafayette, 1977.

MARQUES, J. J. G. S. M.; ALVARENGA, R. C.; CURI, N.; SANTANA, D. P.; SILVA, M. L. N. Índices de erosividade da chuva, perdas de solo e fator erodibilidade para dois solos da região dos cerrados - primeira aproximação. R Bras Ci Solo, v. 21, p. 427434, 1997.

MELLO, G.; BUENO, C. R. P.; PEREIRA, G. T. Variabilidade espacial de perdas de solo, do potencial natural e risco de erosão em áreas intensamente cultivadas. R Bras Eng Agríc Ambiental, v. $10, \quad$ p. $315-322, \quad 2006 . \quad$ http://dx.doi.org/10.1590/S141543662006000200010

MORAIS, L. F. B.; SILVA, V.; NASCHENVENG, T. M. C.; HARDOIN, P. C; ALMEIDA, J. E. L.; WEBER, O. L. S. et al. Índice EI30 e sua relação com o coeficiente de chuva do sudoeste de Mato Grosso. R Bras Ci Solo, v. 15, p. 339-344, 1991.

OLIVEIRA JR., R. C. Índice de erosividade das chuvas na região de Conceição do Araguaia, Pará. Belém: EMBRAPA-CPATU; 1996. (Boletim de Pesquisa, n 165).

OLIVEIRA JR., R.; MEDINA, B. F. A erosividade das chuvas em Manaus (AM). R Bras Ci Solo, v. 14, p. 235-239, 1990.

PEREIRA, H. H. G. Índices de erosividade da chuva: distribuição e relação com a precipitação em Piracicaba - SP. 1983. 70f. Dissertação (Mestrado em Agronomia) Escola Superior de Agricultura Luiz de Queiroz, Piracicaba, 1983.

ROQUE, C. G.; CARVALHO, M. P.; PRADO, R. M. Fator erosividade da chuva de Piraju (SP): distribuição, probabilidade de ocorrência, período de retorno e correlação com o coeficiente de chuva. R Bras Ci Solo, v. 25, p. 147-156, 2001. http://dx.doi.org/10.1590/S0100-06832001000100016

RUFINO, R.; BISCAIA, R. C. M.; MERTEN, G. Avaliação do potencial erosivo da chuva do Estado do Paraná, através de pluviometria. Terceira Aproximação. R Bras Ci Solo, v. 17, p. 439-444, 1993.

SANTOS, G. S.; GRIEBELER, N. P.; OLIVEIRA, L. F. C. Chuvas intensas relacionadas à erosão hídrica. R Bras Eng Agríc e Ambiental, v. 14, n. 2, p. 115-123, 2010.

SCHWAB, G. O.; FANGMEIER, D. D.; ELLIOT, W. J.; FREVERT, R. K. Soil and water conservation engineering. 3. ed. New York: John Wiley \& Sons, 1981.

SILVA, A. M. Rainfall erosivity map for Brazil. Catena, v. 57, p. 251-259, 2004. http://dx.doi.org/10.1016/j.catena.2003.11.006

SILVA, M. L. N.; FREITAS, P. L.; BLANCANEAUX, P.; CURI, N. Índice de erosividade de chuva da região de Goiânia (GO). Pesq Agropec Bras, v. 32, n. 10, p. 977-985, 1997. 
SILVA, M. A. S.; SILVA, M. L. N.; CURI, N.; SANTOS, G. R.; MARQUES, J. J. G. S. M.; MENEZES, M. D. et al. Avaliação e espacialização da erosividade da chuva no Vale do Rio Doce, Região Centro-Leste do Estado de Minas Gerais. R Bras Ci Solo, v. 34, p. 1029-1039, 2010.

SILVA, V. B. S.; KOUSKY, V. E.; SHI, W.; HIGGINS, R. W. An improved gridded historical daily precipitation analysis for Brazil. J Hydromet, v. 8, p. 847-861, 2007. http://dx.doi.org/10.1175/JHM598.1

SILVA, V. C. B.; MACHADO, P. S. SIG na análise ambiental: suscetibilidade erosiva da bacia hidrográfica do Córrego Mutuca, Nova Lima - Minas Gerais. R Geogr, v. 31, n. 2, p. 66-87, 2014.

SODRÉ, G. R. C.; RODRIGUES, L. L. M. Comparação entre estimativa da precipitação observada pela técnica CMORPH e estações meteorológicas do INMET em diferentes regiões do Brasil. R Bras Geog Física, v. 6, n. 2, p. 301-307, 2013.

WISCHMEIER, W. H.; SMITH, D. D. Predicting rainfall erosion losses: A guide to conservation planning. Washington: USDA, 1978. (Agricultural Handbook, 537).

WISCHMEIER, W. H.; SMITH, D. D. Rainfall energy and its relationship to soil loss. Trans Am Geophys, v. 39, p. 285-291, 1958. http://dx.doi.org/10.1029/TR039i002p00285 